\title{
Snacks Online Sales System
}

\author{
Junli Xu \\ College of Information Engineering, Jiangxi University of Technology, Jiangxi Nanchang
}

Keywords: E-commerce; JSP technology; Online snacks sales system

\begin{abstract}
With the rise of e-commerce, online stores are increasingly attracting people's attention, and more and more people choose online store to purchase their needed goods. The system consists of client interface for self-service purchasing and backend interface with administrator management function. The main function of front interface is to achieve commodities browse, purchase, and membership register. The main function of backend interface is to allow administrators to log in to add, modify or delete food the backend with direct control, and it can also be used to view, manage customer orders, and inquire customers' information, as well as add, modify, search, delete some basic information and other operations. Practice has proved that the system is user-friendly and robust.
\end{abstract}

\section{Introduction}

With the rapid development of computer science and technology, online shopping is gradually penetrating into people's lives, and occupies a very important position in people's lives. The online sales system provides a relatively complete online shopping system, similar with Taobao, that can mainly displays basic information about the product, price and so on. Businesses can also use the system to sell merchandise linked to the Internet.

This system is a kind of web-based online snacks selling store. Customers can visit the shop and browse the shop goods, if they are satisfied with the goods online, they can purchase online. The system consists of two parts, one part is selling part of the front page, and the other part is the back part of the administrator login.

Part functions:

1. Registration member refers to becoming a member of the system shop, and they can enjoy the member price of commodities.

2. Product management refers to adding, modifying, deleting, and so on for snacks.

3. Order management is to confirm the order by the foreground and send the corresponding goods.

4. Customer management refers to the operation of the members, such as deleting or adding.

\section{System Analysis}

Preliminary investigation of system. To complete the system better and make sure there is no error or bug on business before making it, it will need sufficient survey work, thus to complete the demand analysis and function realizing of this system.

Feasibility Analysis. The purpose of feasibility analysis is to try to use the minimum cost determining whether the issue can be successfully resolved under the existing technical, 
economic and human capacity and other conditions and whether it is worthwhile to be resolved within the shortest possible time.

Technical feasibility:

Snacks online sales system is a web-based online system, but because C / S framework has some limitations, so the system will use B / S framework to complete the system, and now B / $\mathrm{S}$ architecture has become the best choice for web-based applications development, and it is technically feasible.

Economic feasibility:

After completing the development of this system, if you can put into use, it will provide more opportunities for online business people, and obtain enormous profits from e-commerce, and because the system is small, relatively simple to maintain, so it's more suitable for some people in venture stage or school students. Development and use of the system is feasible economically.

Operational feasibility:

The system has features of robust structure, user-friendly interface, simple operation, intuitive page and easy maintenance, allowing users grasp more easily. Users who are familiar with basic computer operation can use the system. One person can operate, eliminating the need for staff, so this system has operational feasibility

Project demand analysis. Demand analysis is the final phase of software definition. Analyzing the actual demand of users will affect every design phase and validate whether the design results in line with users' demand.

Functional requirement of system:

Online snacks sales system is mainly consisted by two parts: one is foreground client browse interface, and the other part is backend administrator interface, which can realize the basic management of commodity. System module will be introduced in detail as following:

Browse goods: customers can browse the latest recommended snacks and latest added snacks, view and buy them.

Classification by use: click use and enter the snacks searching interface. The results will appear as following picture. Click "import" and the searching interface will show 4 kinds of import food without others.

Buying process: it will show the text buying process of snacks, which is convenient the customers who buy the snacks for the hometime, easy to operate.

Snacks knowledge: it show the text knowledge for buying snacks, to make customers learn the snacks culture better.

Product affiche: show some bulletin information of the store. The administrator will add, modify and delete in the background. The related matters for the products and stores are updated in real time.

Users registration: nonmember user can register as a member through this page by filling in some basic information. The textbox following by red star must be filled in. After completing the contents, click register. If successful, the page will return to the homepage after 5 seconds.

User center: the logged in member can view the information in registration and modify it in this page, except user's name, real name and gender. 
Snacks search: enter the search page, conduct fuzzy query as per the snack name, as well as the classification, eg. Import, domestic product. The default classification include all the classifications. The search results will be shown below.

Shopping cart: when the user selects a goods and click buy, it will add the clicked goods automatically. Users can also modify the goods number in shopping cart. If the user clicks go on shopping, it will return to the front page. Click clear the shopping cart, the selected goods will be cleared. Click submit order, it will form an order number and save it into the database automatically. In the order management of backend interface, the order details will be shown, then the goods in shopping cart will be cleared, too.

Log out and exit: the logged in member will return to the state before logging in by clicking $\log$ out and exit. The goods without being submitted will disappear. If the user want to continue to buy goods, select the goods again.

Backend log in: the administrator logs in the backend management interface by the system backend. If the user name and password are wrong, he cannot log in and the system will prompt "user name or password is wrong!".

affiche management: the administrator can add, modify, delete something by the backend affiche management interface. The change after operation will be shown on the foreground commodity affiche.

Snacks management: the administrator can add, modify and delete snacks. In adding snacks, if the user selects recommend snacks, the snack will appear in the homepage. If not, the snack can only be found by query.

Snacks classification management: in adding, modifying and deleting snacks, the added classifications will show on the foreground interface as per functions, the pull-down list of snacks classification and the added snacks classifications.

Member management: it can be used to delete the registered member.

Inventory sales query: it shows sales volume and inventory and also can be used to inquire as per condition, eg. Inventory volume or sales volume query.

Order query: the administrator can inquire the shopping state of foreground customer service by order query, including member order and nonmember order. Orders can also be inquired by conditions filter, eg. As per snacks name or order quantity.

User management: the administrator can modify the current logged in users' password through user management. After being modified successfully, it will return to the $\log$ in interface and the user should log in with new password.

Log out and exit: click it, the interface will return to log in interface. Log in again.

Business process analysis:

Online snacks sales system is consisted by administrator backend and client foreground. The backend enables the administrator going into the backend management page from home page to operate. Its main functions include affiche management, snacks management, snacks classification management, member management, user management, inventory and sales volume management, order management and so on. Client foreground refers to the client terminal. Customers can enter the home page of online snacks sales system and brows the latest and recommended snacks. They can also view the details. If they need, click buy. If they 
are members, log in first. They will be given member price. Nonmember customers should register first or buy directly.

Data flow diagram:

Data flow analysis describes the flow of system data and process directly based on intuitive graphical, with purpose of discovering and solving the problems in data flowing, and no physical elements in the process. It focuses on data flow and related process, and the method is: map out a set of complete data flow diagram for accounting data processing in corresponding survey according to the business flow chart.

\section{Project general design}

System whole function structure. Considering online snack sales system requirements analysis with the actual situation of online stores, we can get the function structure of the whole system: online snack sales system consists of two parts: the foreground and the backend. The foreground is mainly used to make customers browse commodity information, affiches, buy goods, etc.; the backend is mainly formed by commodity management, order management, bulletin management, etc.

System development platform. As per the contrast analysis of various platforms in the opening report, the development platform is determined as following form after contrast and weight:

Table 1 development platform

\begin{tabular}{|l|l|}
\hline development tool & Myeclipse8.5 \\
\hline language use & JSP \\
\hline database & SQL Server 2000+SP3 \\
\hline development mode & B/S \\
\hline $\begin{array}{l}\text { development } \\
\text { environment }\end{array}$ & jdk1.6、tomcat5.5、Internet Explorer \\
\hline
\end{tabular}

Database structure design. Specific attributes as following:

1. User: user ID, user name, actual user name, password, gender, telephone, email, address, zip code, registration time.

2.Administrator: administrator ID, log in name, password, sex, telephone, email, address, zip code, registration time.

3. Snacks: commodity ID, classification, name, snack introduction, privilege, average price, member price, pictures, reserves.

4. Order: order number, user ID, date, setting time, recipient's name, receiving address, zip code of receiving address, total price.

5. Orders contain snacks contact properties: quantity, item price, total price.

6. Snack materials: ID, name, picture name, category, unit price.

7. Snacks include contact properties: quantity.

8. affiche: affiche number, title, content, adding date.

9. Administrators managing user attributes: time.

10. Browse attributes: user ID, product ID, latest time, accumulative total number. 
11. The administrator processing order properties: order confirmation, confirm time.

12. The affiche management attributes: updated date.

Database structure design:

As one of the most important part of the whole system, database structure design is used to realize various operation, which will be introduced as following respectively.

(1) Administrator form is mainly used to record related information of the administrator.

Table 2 administrator form

\begin{tabular}{|l|l|l|l|}
\hline field name & data type & null or not & $\begin{array}{l}\text { description } \\
\text { instruction }\end{array}$ \\
\hline id & Int(4) & no & $\begin{array}{l}\text { administrator } \\
\text { number, main key }\end{array}$ \\
\hline Name & Varchar(50) & yes & log in user name \\
\hline Pwd & Varchar(50) & yes & log in pass word \\
\hline quanxian & Int(4) & yes & owned permission \\
\hline
\end{tabular}

(2) affiche is used to record the basic information of affiche.

Table 3 affiche form

\begin{tabular}{|l|l|l|l|}
\hline field name & data type & null or not & $\begin{array}{l}\text { description } \\
\text { instruction }\end{array}$ \\
\hline Id & Int(4) & no & $\begin{array}{l}\text { affiche number, main } \\
\text { key }\end{array}$ \\
\hline Name & Varchar(200) & yes & affiche title \\
\hline Content & Varchar(2000) & yes & affiche content \\
\hline times & Datetime(8) & yes & affiche time \\
\hline
\end{tabular}

(3) Goods is mainly used to record basic information of snacks.

Table 4 affiche form

\begin{tabular}{|l|l|l|l|}
\hline field name & data type & null or not & description instruction \\
\hline Id & Int(4) & no & goods number, main key \\
\hline Name & Varchar(200) & yes & goods name \\
\hline locality & Varchar(50) & yes & goods producing area \\
\hline Dates & Varchar(200) & yes & date added \\
\hline Indexs & Varchar(100) & no & recommendation index \\
\hline Price & $\operatorname{Varchar}(50)$ & yes & general price \\
\hline Storage & Int(4) & yes & inventory \\
\hline Brief & $\operatorname{Varchar}(500)$ & yes & goods information \\
\hline Type & $\operatorname{Int}(4)$ & yes & usage (import) \\
\hline Tate & $\operatorname{Int}(4)$ & yes & goods type \\
\hline Sums & $\operatorname{Int}(4)$ & yes & sales volume \\
\hline Imgpath & $\operatorname{Varchar}(200)$ & yes & goods picture path \\
\hline Tuijian & $\operatorname{varchar}(50)$ & yes & recommend or not \\
\hline pricel & $\operatorname{varchar}(50)$ & yes & member price \\
\hline
\end{tabular}

(4) Orders is mainly used to record basic information of snacks. 
Table 5 orders form

\begin{tabular}{|l|l|l|l|}
\hline field name & data type & null or not & $\begin{array}{l}\text { description } \\
\text { instruction }\end{array}$ \\
\hline Id & Int(4) & no & $\begin{array}{l}\text { order number, main } \\
\text { key }\end{array}$ \\
\hline Name & Varchar(50) & yes & buyer name \\
\hline Address & Varchar(200) & yes & address \\
\hline Phone & Varchar(50) & yes & telephone \\
\hline goodid & Int(4) & yes & ID goods ID \\
\hline Sum & Int(4) & yes & buying quantity \\
\hline times & Datetime(8) & yes & buying time \\
\hline
\end{tabular}

(5) Tates is used to record basic information of snacks.

Table 6 tates

\begin{tabular}{|l|l|l|l|}
\hline field name & data type & null or not & $\begin{array}{l}\text { description } \\
\text { instruction }\end{array}$ \\
\hline Id & Int(4) & no & $\begin{array}{l}\text { classification } \\
\text { number, main key }\end{array}$ \\
\hline Name & Char(10) & yes & classification name \\
\hline
\end{tabular}

(6) Types form is used for basic information of snacks.

Table 7 type form

\begin{tabular}{|l|l|l|l|}
\hline field name & data type & null or not & $\begin{array}{l}\text { description } \\
\text { instruction }\end{array}$ \\
\hline Id & Int(4) & no & $\begin{array}{l}\text { type number, main } \\
\text { key }\end{array}$ \\
\hline name & Char(10) & yes & type name \\
\hline
\end{tabular}

(7) Types form is used for basic information of snacks.

Table 8 type form

\begin{tabular}{|l|l|l|l|}
\hline \multicolumn{1}{|c|}{$(8)$ field name } & \multicolumn{1}{|c|}{$(9)$ data type } & \multicolumn{1}{c|}{$(10)$ null or not } & $\begin{array}{l}\text { (11 }) \text { description } \\
\text { instruction }\end{array}$ \\
\hline Id & Int(4) & no & member ID, main key \\
\hline Name & Varchar(50) & yes & member name \\
\hline Pwd & Varchar(50) & yes & log in password \\
\hline Realname & Varchar(50) & no & actual name \\
\hline Sex & Varchar(50) & yes & gender \\
\hline Age & Varchar(50) & yes & age \\
\hline Card & $\operatorname{Varchar}(50)$ & yes & ID number \\
\hline Address & $\operatorname{Varchar}(200)$ & yes & address \\
\hline Phone & $\operatorname{Varchar}(50)$ & yes & telephone \\
\hline Email & $\operatorname{Varchar}(100)$ & yes & email \\
\hline Code & $\operatorname{Varchar}(50)$ & yes & zip code \\
\hline type & $\operatorname{Int}(4)$ & yes & type \\
\hline
\end{tabular}




\section{Detailed design}

Javabean application design of processing Chinese characters and functions browse. Javabean application design of processing Chinese characters

Like many programs, the system will involve the string processing problems. The commonly used method is javabeans. String processing problems include displaying correctly and storage pages as well as all the string concerning Chinese in database, including enter, line feed spaces of the string. We will get familiar with the questions by following code.

1. Messy code

Public String WrongStr(String str)\{

If $($ str $==$ null $)\{$

Str="';

\}

Else \{

Try\{

Str=(new String(str.getBytes(“iso-8859-1"),"GB2312”)).trim();

\}

Catch(Exception e) \{

e.printStackTrace(System.err)

\}

\}

Return str;

\}

2. Process problems of enter and line feed

public String tabStr(String str1)\{

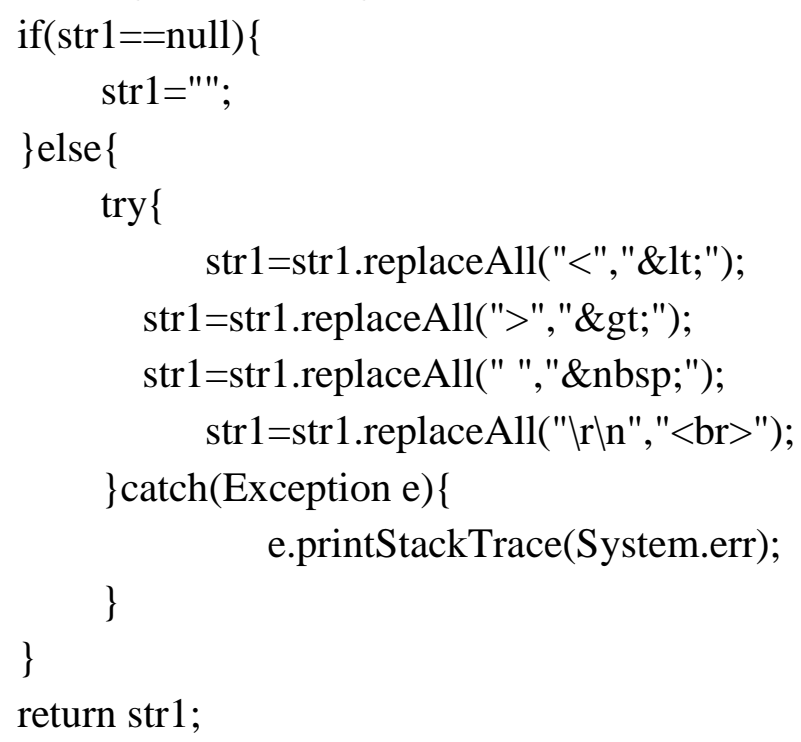

Functions realization. Homepage design:

Home page is the first interface for a customer logging in this system. You can see the newly updated snacks and latest recommended snacks from the screen, as well as the functions of this system. After logging in, customers can operate this system easily based on their 
understanding of home page. First of all, users can browse the latest snacks and recommended snacks. If customers want to understand the detailed information, they can directly go into the snacks interface for detailed information, or operate according to the above prompt functions.

the interface includes four main parts:

top.jsp: contain the top logo image, system name picture and [home page], [buying snacks process], [snacks knowledge], [product announcement], [user registration], [user center], [snacks search], [shopping cart], [cancel out] and other indexes.

left1.jsp: Contain the left side "functional classification" tree structure.

copyright..jsp: contain the bottom version right footnote. Even each interface has copyright.jsp.

Embed pictures in the homepage index.jsp: the newly added snacks and recommended snacks. Administrators add snacks from backend and select them as recommendation, then the snacks will be loaded for customer browse.

related code as following:

Left1.jsp type tree:

$<\%$

If(type!=null $)\{$

For(int $\mathrm{i}=0 ; \mathrm{i}<$ type.size ()$; \mathrm{i}++)\{$

Arraylist alrow $=($ arraylist $)$.type.get $(\mathrm{i})$;

$\%>$

\}

\}

Member log in:

The function ensures the customers buy goods after browsing goods information. And the price is member price. Customers can only log in successfully by inputting right user name and password. When customers quit, session will be cleared.

User registration:

It is a registration platform for nonmember users. It is free. After registration, the customer will be treated as a member. For example, the buying price will be lower than common people. They can also attend the regular activities held by the system. For details, customers can learn from the notice.

Information view and modification:

Customers can view and modify their own information in registration in user center except user name, actual name and gender.

Shopping cart:

As the name implies, shopping cart is a virtual store as a container for customers purchasing goods. This is one of the most important module of online shopping. Customers can buy, add, modify, or delete the goods by shopping cart.

Submit order: 
Submit order means after choosing goods and clicking the submit button under shopping cart, it will create an order number in database. The administrator can enter order management after logging in the backend to dispatch and deliver goods of the order.

\section{Conclusions}

The system analyzes problems based on the actual conditions from the the customers' point of view to make system operation easier, more reasonable and humanized. The paper mainly describes project summary, system analysis, general design and detailed design. The mainly applied development tools is myeclipse8.5 using JSP and javabean. The database is SQL SERVER2000. Using the software and powerful development language, we can complete online snacks sales system better. Although the functions and the interface are not complete, the basic functions are met,which is enough to meet the shopping requirements for shopping.

To sum up, online snacks sales system has met the design requirements. In the developing process, the author will search for materials actively for unknown questions, and ask others for advice to make the programming thought improved. So the author gets a lot of experience and improve the synthetic ability greatly.

\section{Acknowledgements}

This work was financially supported by project of Technology Department of Jiangxi Province [No 20143BBM26048] and the project of Technology Department of Jiangxi Province [No 2013BBE50051] also gives us lots of help.

\section{References}

[1] Java Development Practice, Li Xinghua, Tsinghua University Press, 2009

[2] Project Course of Java Programming Design, Zhang Xingke, Ji Wuchang, Renmin University Of China Publishing House, 2010

[3] Java Programming Design Practice, Li Zongjun, China Water Conservancy and Hydropower Press, 2010

[4] Java Application Development Books - Based on Myeclipse Platform + Spring + Struts + Hibemate Mainstream Development Framework, Sun Gengxin, China Railway Publishing House, 2010

[5] Java Language Description of Data Structure And Algorithm Analysis, Weiss, m., Mechanical Industry Publishing House, 2009

[6] Introduction of Database Systems, Abraham Silberschatz; Henry F.K orth. S.S udarshan, Mechanical Industry Publishing House, 2012

[7] Database Technology and Application, Liang Xiaohong; Zhang Denghong, Renmin University of China Publishing House, 2012 
[8]SQL Server 2000 Management and Application Development Tutorial, Mr. Wong, People's Posts and Telecommunications Publishing House, 2009 